\title{
Sleep deprivation in nursing students: The negative impact for quality and safety
}

\author{
Cynthia M. Thomas ${ }^{* 1}$, Constance E. Mclntosh ${ }^{1}$, Ruth Ann Lamar ${ }^{2}$, Roberta L. Allen ${ }^{1}$ \\ ${ }^{1}$ School of Nursing, Ball State University, Muncie, Indiana, United States \\ ${ }^{2}$ School of Nursing, Western Governors University, Indianapolis, Indiana, United States
}

Received: October 31, 2016

Accepted: December 15, $2016 \quad$ Online Published: January 3, 2017

DOI: $10.5430 /$ jnep.v7n5p87

URL: http://dx.doi.org/10.5430/jnep.v7n5p87

\begin{abstract}
Objective: The purpose of this pilot study was to understand nursing students' perception of the relationship between sleep deprivation and learning, and personal and patient safety when in a clinical or work setting.

Methods: Design: The researchers used a cross-sectional correlational design. Setting: The study was conducted in a Midwestern state university school of nursing with an average of 400 undergraduate pre-licensure nursing students. Sample: All 328 undergraduate pre-licensure nursing students were invited to participate in the study. The convenience sample of 179 (response rate of 55\%) pre-licensure, nursing students completed the study. Methodology: The Sleep Deprivation of Nursing Students, a 4-point Likert scale questionnaire, consisted of demographic questions and forty-five questions on personal sleep habits, caffeine/stimulant use, and sleep inducing aids, motor vehicle safety, spare time activities, and safety during work and clinical experiences.

Results: One hundred and fifty-five $(n=155)$ students needed seven or more hours of sleep daily to feel rested, but received less than 5 hours/day. All participants reported $(n=179)$ feeling sleep deprived. Sleep inducing aids were used by $(n=56)$ participants, and $(n=35)$ took stimulants to stay awake. Students $(n=166)$ worked 8 or more hours at a job, and $(n=158)$ had at some 12 hour school clinical rotations, and $(n=64)$ reported a combined clinical and work of five to greater than 12 consecutive days. Students $(n=172)$ believed they provided safe practice at work and $(n=174)$ and safe practice in a clinical setting. Some students reported being awake 17-19 hours. The majority of students $(n=144)$ believed 12-hour-clinicals were too long, yet more than half of the students preferred 12-hour work and clinical experiences.

Conclusions: Nursing students may lack the knowledge that chronic sleep deprivation may result in personal and patient safety issues when in a clinical or work setting. Students are potentially exposing themselves to acute and chronic health problems as a result of sleep deprivation and the use of substances to remain awake or obtain sleep. Nurse educators and nurse managers must collaborate to reduce the number of consecutive clinical and work shifts, limit overtime hours, and better educate students on the negative impact of sleep deprivation.
\end{abstract}

Key Words: Sleep deprivation, Nursing student, Quality and safety

\section{INTRODUCTION}

Long work hours, consecutive shifts, and sleep deprivation in physicians and registered nurses have been associated to negatively impact patient safety. ${ }^{[1-4]}$ However, little information is available relating nursing students' sleep, work habits, and safety. Unhealthy habits formed during college years States.

*Correspondence: Cynthia M. Thomas; Email: cmthomas@bsu.edu; Address: School of Nursing, Ball State University, Muncie, Indiana, United 
may later result in a lifetime of chronic health problems and for nurses adversely impact quality of care and patient safety. Nursing students may be more susceptible to developing poor sleep habits as a result of stringent program commitments and a lack of knowledge about the acute and chronic health consequences that may carry over into professional practice.

Historic studies as well as more recent research have confirmed sleep loss negatively affects performance of cognitive tasks, indicating slower reaction times and poor decisionmaking, as well as cardiac, metabolic, and gastrointestinal issues ${ }^{[5-7]}$ while the sleep-deprived persons do not realize the extent to which they are affected or the long term impact to health. ${ }^{[3,8]}$ College students, in particular, experience the pressing need to work and maintain social lives while balancing extensive class and study time. Hershner and Chevin ${ }^{[9]}$ reported that $50 \%$ of college students suffer from daytime sleepiness, and $70 \%$ do not obtain sufficient sleep impacting grade point averages, the risk of academic failure, auto accidents, learning and memory. Researchers also found that a significant proportion of nurses and nursing students suffer from sleep abnormalities and associated medical issues (headaches, tiredness, back pain, gastroesophageal reflux, insomnia, and depression), as well as lower grades in those with significant lack of sleep. ${ }^{[3,10,11]}$ Additionally, the circadian system of young people supports late nights for sleeping and late mornings or early afternoons for waking. Daytime sleepiness due to lack of natural sleep reduces academic achievement, learning, and behavioral performance. ${ }^{[9,12]}$ The changes to behavioral performance can result in increased risk-taking, emotional disorders, and substance abuse, all of which increase the risk of accidents and injuries.

Furthermore, college students typically have irregular schedules, little or no adult supervision, and easy access to overthe-counter, prescription, and recreational drugs. ${ }^{[13]}$ Challenging daily demands of college life combined with sleep deprivation can lead to a stimulation-sedation loop cycle: caffeine and other stimulant use during the day for wakefulness and depressant use at night to neutralize stimulant effect and to aid in sleep. ${ }^{[9]}$ Alarmingly, four of five college-age students engage in alcohol use with up to $40 \%$ admitting to binge drinking, using alcohol as a sleep aid, or using caffeine late at night to prevent or delay sleep. ${ }^{[14,15]}$ Close to $90 \%$ of young people entering drug rehabilitation programs admit to self-medicating for the promotion of wakefulness and sleep to deal with erratic college schedules. ${ }^{[16-18]}$

Lockley, Barger, Ayas, Rothschild, Czeisler, and Landrigan's and Scott et al.'s studies found that nurses working 12.5 hours or more made significantly more errors and had an increased risk for needle stick injury, hepatitis, HIV, and blood borne illness and regretted some clinical decisions. ${ }^{[7,19]}$ Scott et al. found that nurses working the night shift, those working 12-hours or greater, or were males had the most decision regret. ${ }^{[7]}$ Lockley et al. also found that physicians working consecutive 24-hour shifts made more serious errors, attention failures, had more needle stick injuries, and doubled their risk of having a motor vehicle accident. ${ }^{[19]}$

While the literature presents a persuasive picture of the need for sleep and the impact sleep deprivation can have on students, and healthcare practitioners, a dearth of research surrounding, specifically, nursing students, sleep deprivation, and associated impact of sleepiness on health and safety exists. Therefore, the research question for this pilot study was, "What are nursing students perception of the relationship between nursing students' sleep habits and learning, and personal and patient safety when in a clinical or work setting?"

\section{METHODS}

A cross-sectional correlational design was used for the pilot study. A convenience sample of 328 pre-licensure nursing students from a Mid-western university was sought for the study. Internal Review Board (IRB) approval was obtained through the university. The anonymous questionnaire, informed consent, and all study materials were sent via Qualtrics, ${ }^{[20]}$ an online survey method, to all undergraduate nursing students via students' university email accounts. Students had been or were currently enrolled in a nursing course with a clinical component. The data will be stored in a locked file cabinet in the researchers office for a year period of time after study completion.

\subsection{Participants}

Three hundred twenty-eight pre-licensure undergraduate nursing students in a Mid-western university were invited to participate in the study. Of the convenience sample ( $\mathrm{n}=$ 328), 182 students responded and 179 completed the study, resulting in a 55\% response rate. Eighty-eight percent of the participants $(n=157)$ were nineteen to twenty-four years of age. The majority of the students were seniors $(n=164)$, female $(\mathrm{n}=169)$, and single $(\mathrm{n}=163)$ with no children ( $\mathrm{n}$ $=164)$. One hundred fifteen $(n=115)$ participants drove to work 0-15 minutes, $\mathrm{n}=23$ participants drove $16-30 \mathrm{~min}$ utes to work, only 22 participants drove $31-45$, and $n=12$ participants drove greater that 45 minutes to work.

\subsection{Instrumentation}

The questionnaire was developed by the researchers and titled, Sleep Deprivation of Nursing Students, and included demographic and 45 survey questions. After extensive review 
of the literature questions were developed by four researchers using expert judgment resulting in content validity. Section (A) of the questionnaire addressed general sleep habits, (B) addressed school clinical and personal work experiences, section (C) addressed motor vehicle use, after working and program clinical experiences, part (D) of the questionnaire addressed what students do in their spare time, and (E) their experiences around safety during work and clinical experiences. The questionnaire was based on a 4-point Likert scale ranging from never, sometimes, often and always, and degrees of time or distance.

\subsection{Procedures}

The 328 undergraduate, pre-licensure, nursing students were emailed an invitation letter to participate. The questionnaire was sent by an Internet Technology (IT) technician, serving as part of the team, using the student's university email address and Qualtrics, an online survey delivery method. There were no incentives provided for completing the study. Three email reminders were sent to the participants during the six-week study completion period. The data analysis was completed by four researchers and a university statistician.

\subsection{Data analysis}

Participants were asked to rate their responses to posed questions or statements on a 4-point Likert scale. Researchers calculated the percentage for each question or statement or groups of like questions/statements. The research team analyzed the question results and like groups of questions to determine their relationship to one another. All data analysis was completed using IBM SPSS Statistics for the Macintosh, Version 22.0. There were similar groups of questions included within specific categories of the questionnaire such as, general sleep habits, work and school clinical experiences and sleep, travel time, and accident history after work or a clinical experience, travel distance, how personal time is spent when not working or in a school clinical experience, and safety when working or engaged in a school clinical experience.

\section{RESUlts}

One hundred and eighty-two students agreed to participate, and 179 students completed the study questionnaire. When asked about general sleep habits, 24 participants believed they needed 5-6 hours of sleep, 120 participants required 7-8 hours of sleep, and 35 participants needed greater than 8 hours of sleep to feel rested. However, the majority of participants $(n=107)$ only slept 5-6 hours before class or clinical experience and often felt sleep deprived. One hundred and thirty-two participants believed they would perform better academically if more sleep was obtained. To stay awake, 152 participants consumed some form of caffeine, while a third consumed some form of sleeping aids. The majority of participants $(n=158)$ had school clinical hours of $7-12$ or greater. There were 95 student participants not working in a healthcare related area, and 51 participants were not working at the time of the study. The average work hours were 5-12 hours per day during the academic year.

There were four questions related to feelings of being tired and falling asleep at work or clinical and three questions related to 12-hour shifts worked during employment or a clinical experience. One hundred and fifty-seven participants felt tired while working, and 168 felt tired during the required school clinical hours. Twenty-three participants reported having fallen asleep at their job or during a clinical experience. More than half of the participants preferred to work and have school clinical experiences of 12-hours in sharp contrast to 144 students believing that 12 -hour shifts were too long for clinical experiences.

There were eight questions about driving a motor vehicle when feeling tired after work or a clinical experience of 12 or more hours. All of the student participants felt tired when driving a motor vehicle after working or a clinical experience and over half had either fallen or nearly fallen asleep while driving after working or a clinical experience. Thirty-three participants reported that they had almost had a motor vehicle accident after a 12-hour clinical experience. There were two questions related to the number of miles driven after work or clinical. Ninety-nine participants drove 5 to greater than 12 miles to work, and 121 drove 5 or greater than 12 miles to a clinical experience. When given the time 170 participants tried to catch up on sleep.

Eight questions were directed to safe practice when working or in a school clinical experience. Almost all student participants believed they provided safe practice at work $(n=172)$ or during a clinical experience $(\mathrm{n}=174)$. Participants did not believe working 12-hour shifts negatively impacted safe practice $(\mathrm{n}=152)$ or safety during school clinical experiences ( $\mathrm{n}$ =145). However, participants did believe that school clinical experiences of 12 hours or more decreased the ability to learn $(n=139)$. There were 63 students who stated that they have worked and also had clinical experiences of 12 hours or more back-to-back shifts. There were $(n=64)$ participants who had combined consecutive days of work and school clinical experiences of five to greater than 10 days (see Table 1). 
Table 1. Sleep study result highlights

\begin{tabular}{|c|c|c|c|c|c|}
\hline \multicolumn{6}{|l|}{ 1A General Sleep Habits } \\
\hline \multirow{3}{*}{$\begin{array}{l}\text { 1a. On average I need-----hours of sleep to feel } \\
\text { rested }\end{array}$} & $0-4$ & $5-6$ & $7-8$ & Greater than 8 & Total \\
\hline & ------ & ------ & ------ & ------ & Responses \\
\hline & 0 & 24 & 120 & 35 & 179 \\
\hline \multirow{3}{*}{$\begin{array}{l}\text { 2a. On average I obtain-----hours of sleep prior to } \\
\text { class }\end{array}$} & $0-4$ & $5-6$ & $7-8$ & Greater than 8 & \multirow{3}{*}{179} \\
\hline & ------ & ------ & ----- & ------ & \\
\hline & 4 & 107 & 65 & 3 & \\
\hline \multirow{3}{*}{$\begin{array}{l}\text { 3a. On average I obtain ----hours of sleep prior to a } \\
\text { clinical experience }\end{array}$} & $0-4$ & $5-6$ & $7-8$ & Greater than 8 & \multirow{3}{*}{179} \\
\hline & ------ & ------ & ----- & ------ & \\
\hline & 37 & 112 & 28 & 2 & \\
\hline \multirow{3}{*}{ 4a. I feel sleep deprived? } & Never & Sometimes & Often & Always & \multirow{3}{*}{179} \\
\hline & ------ & ------ & ------ & ------ & \\
\hline & 0 & 74 & 91 & 14 & \\
\hline \multirow{3}{*}{$\begin{array}{l}\text { 5a. I would perform better academically if I had } \\
\text { more sleep }\end{array}$} & Never & Sometimes & Often & Always & \multirow{3}{*}{179} \\
\hline & ------ & ------ & ------ & ------ & \\
\hline & 3 & 44 & 47 & 85 & \\
\hline \multicolumn{6}{|c|}{ 1B. Nursing Program Clinical Hours and Work Experiences } \\
\hline \multirow{3}{*}{ 1b. My school clinical experience hours are----- } & $1-4$ & $5-6$ & $7-12$ & Greater than 12 & \multirow{3}{*}{$\begin{array}{l}\text { Total } \\
\text { Responses } \\
177\end{array}$} \\
\hline & ------ & ------ & ----- & ------ & \\
\hline & 2 & 17 & 106 & 52 & \\
\hline \multirow{3}{*}{$\begin{array}{l}\text { 2b. I have been employed -----hours during the } \\
\text { academic year }\end{array}$} & Not working & $1-4$ & $5-8$ & 8-12 & \multirow{3}{*}{177} \\
\hline & ------ & ------ & ------ & ------ & \\
\hline & 51 & 6 & 20 & 100 & \\
\hline \multirow{3}{*}{ 3b. I am employed in a healthcare related field } & Yes & No & & & \multirow{3}{*}{177} \\
\hline & ------ & ------ & & & \\
\hline & 82 & 95 & & & \\
\hline \multirow{3}{*}{ 6b. I feel tired while working } & Never & Sometimes & Often & Always & \multirow{3}{*}{164} \\
\hline & ------ & ------ & ------ & ------ & \\
\hline & 7 & 79 & 65 & 13 & \\
\hline \multirow{3}{*}{$\begin{array}{l}\text { 7b. I feel tired during my school clinical } \\
\text { experience }\end{array}$} & Never & Sometimes & Often & Always & \multirow{3}{*}{170} \\
\hline & ------ & ------ & ------ & ----- & \\
\hline & 2 & 72 & 80 & 16 & \\
\hline \multicolumn{6}{|l|}{ E. Safety at Work or Clinical Experience } \\
\hline \multirow{3}{*}{ 1e. I believe I provide safe practice at work } & Never & Sometimes & Often & Always & \multirow{3}{*}{$\begin{array}{l}\text { Total } \\
\text { Responses } \\
173\end{array}$} \\
\hline & ------ & ------ & ------ & ------ & \\
\hline & 1 & 2 & 62 & 108 & \\
\hline & Never & Sometimes & Often & Always & \\
\hline clinical experience & ------ & ------ & ------ & ------ & 174 \\
\hline & 0 & 1 & 55 & 118 & \\
\hline & Never & Sometimes & Often & Always & \\
\hline 3e. Working 12 -hour shitts does not negatively & ------ & ------ & ------ & ------ & 168 \\
\hline & 16 & 80 & 49 & 23 & \\
\hline & Never & Sometimes & Often & Always & \\
\hline more do not impact safe practice & ------ & ------ & ------ & ------ & 170 \\
\hline & 25 & 75 & 49 & 21 & \\
\hline
\end{tabular}

\section{Discussion}

Many nursing students need or choose to work while in college and/or during clinical activities requiring up to 12-hour shifts. Also, faculty are finding it increasingly difficult to secure clinical sites and may need to have students drive farther distances, ${ }^{[21]}$ as well as use weekend and night clinical shifts as an alternative to day shifts. The longer clinical hours coupled with longer commuting may place students in situations that jeopardize their safety as well as compromise patient safety. While there has been much discussion 
about the difficulty new registered nurses are experiencing with the role transition to professional practice, there are still important questions being asked about preparation for the transition. ${ }^{[22]}$ We found that all of the student participants were or had been working at some time during the college experience.

The majority of the participants $(87 \%)$ needed 8 or more hours sleep to feel rested but $62 \%$ obtained 6 hours or less before class time, and more alarming, 83\% received 6 hours or less before a clinical experience. This potentially places the students at risk for less than optimal learning in the classroom and more significantly creates potential safety issues in the clinical environment. Caruso and Scott, ArslanianEngoren and Engoren, ${ }^{[2,7]}$ have found that cognitive abilities, reaction time, and decision-making are all negatively impacted by lack of sleep and 12-hour shifts. Students may mistakenly believe they are safe in a clinical environment with less than 5 hours of sleep but the research strongly indicates they are not. All of the participants felt sleep deprived and believed they would perform better academically if they had more sleep.

To combat the need for sleep participants admitted consuming caffeine or took stimulants and then consumed sleeping aids to fall or stay asleep. This pattern may lead to future chronic health issues and potential addiction. ${ }^{[16-18]}$ What is not known is the type of caffeine or stimulants being consumed, such as the current trend of highly caffeinated energy drinks, coffee, sodas, or pills. This is alarming since Bootzin and Stevens' $(2005)^{[16]}$ study, and the current rise in illicit drug use, indicates that up to $90 \%$ of college age people entering drug rehabilitation programs admitted to self-medicating to stay awake and then to obtain sleep. This behavior may carry over to the work environment when the now professional nurse is working multiple 12-hour shifts, potentially leading to chronic health, addiction, and safety issues as confirmed by Hershner and Chervin, and Sivertsen et al. ${ }^{[9,23]}$

In spite of the current research indicating increased error rates and safety issues with 12-hour shifts participants still believed they engaged in safe practice at work and during a clinical experience. Participants $(90 \%)$ also believed work or clinical experiences (85\%) of 12-hour shifts or more did not impact safety, and $82 \%$ of the participants did not believe 12 hour clinical experiences decreased their ability to learn. This finding is the opposite of Hershner and Chevin's study findings that $50 \%$ of college students suffer from daytime sleepiness, which results in lower GPA's and the ability to learn, negatively impacts motor vehicle driving, and influences their moods. ${ }^{[9]}$ There is also support that fatigue results in an organizations financial loss due to errors, absenteeism, loss of productivity, turnover, disability, death and increased risks for decreased patient safety and increased motor vehicle accidents. $^{[2]}$

Our findings are consistent with Luckhaupt, Tak, and Calvert's (2010) report that at least $32 \%$ of healthcare employees receive 6 hours or less of sleep. ${ }^{[24]}$ This is a disturbing trend that not only impacts the health and safety of the employee, but also the patients and supports the findings of this study. Nursing student's safety should be at the forefront of nurse educators and employers when engaging students in school and work requirements. We must teach our students about proper sleep and health habits that will hopefully carry over into their professional careers.

\subsection{Limitations}

This pilot study used a convenience sample at a Mid-western university, and the results may not be generalizable to other schools of nursing of differing sizes, especially those in large urban areas. Also, due to the unique nature of the study, the authors developed a new instrument that needs further testing for validity and may need changes to some questions to obtain more detailed answers. Lastly, although the researchers strived to convey to potential participants that no punitive actions or rewards would be given if the survey was completed or not, students still may have perceived that they needed to participate in the study to satisfactorily meet program or course requirements.

\subsection{Implications and recommendations for nursing}

This study investigated undergraduate pre-licensure nursing students' self-reports of sleep habits, academic performance, use of stimulants, the number of employment and clinical hours, feelings of tiredness, performance in the clinical setting and driving and adverse effects of fatigue and driving on participants. Students obtaining less than optimal sleep, remaining awake 18-19 hours per day, and consuming substances to stay awake or fall asleep impacts their ability to learn, clinical judgment, and may lead to substance abuse, health issues, and accidents. Educators must determine how many clinical activities should include 12-hour shifts that have been well documented to lead to increased errors, decreased cognition, sleepiness, and motor vehicle accidents. The results indicated that half of the students (53\%) were not employed in a healthcare related area. As educators and clinicians should we be concerned about this. Further inquiry needs to take place as to why students who are working towards a professional healthcare position are not seeking employment in healthcare related fields, while still in school. Could it be that there is a lack of suitable jobs in healthcare facilities? Or, is it possible that students may earn more money 
and have more flexible hours in jobs outside of healthcare. Future research should investigate if employment outside of healthcare is adversely impacting students transition into professional practice, affecting quality of care and astute safety practices.

These findings give us concern and raise additional questions that while 12-hour shifts are the norm for the professional nurse, 12-hour shifts may not be the best option for all levels of nursing students. It is the responsibility of the nurse educator and employer to educate nursing students on the dangers of sleep deprivation, use of substances to aid sleep or wakefulness and long, consecutive work and clinical hours. This can be accomplished by holding workshops, providing Fact Sheets, gradually increasing clinical hours, and having students and employers monitoring the combined number of days and hours worked and engaged in a clinical requirement per week. In addition, educators and nurse managers must work collaboratively to provide the best schedule for the student/employee. Limited personal work hours during the time students have clinical requirement rotations seems to be a logical and reasonable solution. While this study was limited to one group of students in a Mid-western university future research on a national level is planned to strengthen the validity and reliability of the newly developed questionnaire and gain more information about nursing students sleep habits on a broader scale.

\section{Conclusion}

Over 30 years of research has shown the negative effects of sleep deprivation, circadian misalignment, and human performance in physicians and nurses. There is little, if any, investigation to date, into the effects of those same variables on nursing students. Post-study, we conclude that it is incumbent that educators realize the responsibility to recognize how; sleep, employment, and clinical variables affect personal safety and overall clinical judgment. Educators and employers may need to collaborate to determine if limits on work and clinical experiences are needed and to teach students about proper sleep, health habits, and safety. The transition to professional practice may be improved, and students may develop better health habits that carry over to their professional careers and personal lives. Finally, providing nursing students with the information about sleep deprivation and safety may also better ensure patients receive quality and safe care.

\section{ACKNOWLEDGEMENTS}

Research dissemination was partially funded by the Indiana Organization of Nurse Executives (IONE).

\section{CONFLicts OF InTEREST Disclosure}

The authors declare that there is no conflict of interest.

\section{REFERENCES}

[1] American Nurses Association. Revised position statement, Addressing nurse fatigue to promote safety and health: joint responsibilities of registered nurses and employers to reduce risks. Silver Springs, MD; 2014 Sept 10. Position statement; Available from: http: //www. nursingworld.org/Addressing-Nurse-F atigue-ANA-Position-Statement.pdf

[2] Caruso CC. Better sleep: Antidote to on-the-job fatigue. American Nurse Today 2012; 7(5). Available from: http://www .americannursetoday.com/better-sleep-ant idote-to-on-the-job-fatigue/

[3] Eanes L. The potential effects of sleep loss on a nurse's health American Journal of Nursing. 2015; 115(4): 34-42. PMid:25793430 https://doi.org/10.1097/01.NAJ .0000463025.42388.10

[4] Joint Commission. Health care worker fatigue and patient safety. Sentinel Event Alert 2011; 48.

[5] Breus MJ. The night shift, nurses and sleep deprivation. Psychology Today. 2011; Available from: https: //www.psychologytoday.com/blog/sleep-newzzz/201105 /the-night-shift-nurses-and-sleep-deprivation

[6] Sagaspe P, Sanchez-Ortuno M, Charles A, et al. Effects of sleep deprivation on color-word, emotional, and specific stroop interference and on self-reported anxiety. Brain and Cognition. 2006; 60, 76-87.

[7] Scott LD, Arslanian-Engoren C, Engoren MC. Association of sleep and fatigue with decision regret among critical care nurses. American
Journal of Critical Care Nurses. 2014; 23(1): 13-23. PMid:24382613 https://doi.org/10.4037/ajcc2014191

[8] Trinkoff A, Geiger-Brown J, Brady B, et al. How long and how much are nurses now working? American Journal of Nurses. 2006; 106(4): 60-71. https://doi.org/10.1097/00000446-20060 4000-00030

[9] Hershner SD, Chervin RD. Causes and consequences of sleepiness among college students. Nature and Science of Sleep. 2014; 6: 73-84. PMid:25018659

[10] Geiger-Brown J, Trinkoff AM. Is it time to pull the plug on 12 hour shifts? Journal of Nursing Administration. 2012; 40(3): 100-102.

[11] Mayo Clinic Staff. Psychological fatigue. Mayo Clinic 2014. Available from: http://www.mayoclinic.org/symptoms/fatigue/ basics/definition/sym-20050894

[12] Curcio G, Ferrara M, De Gennaro L. Sleep loss, learning capacity and academic performance. Sleep Medicine Reviews. 2006; 10: 323-37. PMid:16564189 https://doi.org/10.1016/j.smrv. 2005.11 .001

[13] Arria AM. Compromised sleep quality and low GPA among college students who use prescription stimulants non-medically. Sleep Medicine. 2011; 12(6): 536-537. PMid:21645871 https://doi. org/10.1016/j.sleep.2011.04.001

[14] American College Health Association. American College Health Association: National College Health Assessment II Reference Group Executive Summary Spring 2012. Hanover, 
MD: American College Health Association. Available from: http://www .acha-ncha.org/docs/ACHA-NCHA-II_Refere nceGroup_ExecutiveSummary_Spring2012.pdf

[15] Savage L. Student health and effects of sleep deprivation: Best study habits include adequate sleep. Cengage Brainac. 2013. Available from: http://www. cengagebrain.com/blog/2013/03/stud ent-health-and-effects-of-sleep-deprivation-best-s tudy-habits-include-adequate-sleep/

[16] Bootzin R, Stevens S. Adolescents, substance abuse, and the treatment of insomnia and daytime sleepiness. Clinical Psychology Review. 2005; 25: 629-44. PMid:15953666 https ://doi .org/10.1 016/j.cpr.2005.04.007

[17] Johnston LD, O'Malley PM, Bachman JG, et al. Monitoring the Future national survey results on drug use, 1975-2006: Volume II, College students and adults ages 19-45 (NIH Publication No. 07-6206). Bethesda, MD: National Institute on Drug Abuse 2007. Available from: http://monitoringthefuture.org/pubs/mon ographs/vol2_2006.pdf

[18] Substance Abuse and Mental Health Services Administration. Results from the 2012 National Survey on Drug Use and Health: Summary of national findings (NSDUH Series H-46, HHS Publication No. (SMA) 13-4795) 2013. Rockville, MD: Author.

[19] Lockley SW, Barger LK, Ayas NT, et al. Effects of heath care provider work hours and sleep deprivation on safety and performance. The Joint Commission on Accreditation of Healthcare Organizations. 2007; 33(11): 7-18.

[20] Qualtrics.com Qualtrics: The worlds leading research \& insight platform 2016.

[21] American Association of Colleges of Nursing. Nursing faculty shortage 2015. Available from: http://www.aacn.nche.edu/medi a-relations/fact-sheets/nursing-faculty-shortage

[22] Thomas CM, McIntosh CE, Mensik JS. A Nurses Step by step Guide to Transitioning to the Professional Nurse Role. Sigma Theta Tau International. Indianapolis, Indiana. 2015.

[23] Sivertsen B, Lallukka T, Salo P, et al. Insomnia as a risk factor for ill health: Results from the large population-based prospective HUNT study in Norway. Journal of Sleep Research 2014; 23: 124-32. PMid:24635564 https://doi.org/10.1111/jsr.12102

[24] Luckhaupt SE, Tak SW, Calvert GM. The prevalence of short sleep duration by industry and occupation in the National Health Interview Survey. Sleep. 2010; 33: 149-159. PMid:20175398 